\title{
Passive Damping Device for Sandwich Structures
}

\author{
Oliver Romberg*
}

Deutsches Zentrum für Luft- und Raumfahrt (DLR), Robert-Hooke-Straße 7, D-28359 Bremen, Germany

Received: August 5, 2010; Accepted: August 23, 2010; Revised: September 10, 2010

\begin{abstract}
In many technical areas structural vibration loads are safety critical design drivers. Here, the improvement of reliability and safety, the reduction of mass, the extension of service life, as well as the reduction of manufacturing cost are desired. Especially lightweight structural design in general is a compromise between mass and robustness with regard to dynamic loads. The structural stresses and strains due to displacements caused by dynamic loads can be reduced by mechanical damping based on passive or active measures. Passive damping systems do not require electronics, control algorithms, power, actuators, sensors or complex maintenance. The simple physical effect of passive dampers is based on the dissipation of load induced energy. The patent DE10138250 (November 2008) described in the present paper is based on the function of a very simple passive friction-damping device for sandwich structures. Regarding this invention, passive friction elements are placed between the face sheets of composite sandwich panels. The damping effect is verified by simple tests.
\end{abstract}

Keywords: Composite sandwich structures, dynamical loads, friction damping, mechanical load reduction, mechanical structures, passive vibration damping.

\section{INTRODUCTION}

Composite sandwich structures in many kinds of lightweight applications are affected by permanent dynamic loads. For many structures these dynamic loads are decisive for component design. Here, the reduction of mass, the extension of service life, the improvement of structural reliability and safety as well as the reduction of cost for manufacturing and maintenance are desired. One possibility for dynamic stress reduction is the increase of mechanical damping which can be achieved by passive or active measures, e.g. using piezo-actuators. These active devices are complex and require electronics, control technique, sensitive sensors and actuators as well as maintenance. Moreover, a reliable application of active dampers for higher temperatures is questionable. Suppression of dynamic loading can also be obtained by using a simple, lightweight and reliable method of friction based passive damping.

Passive friction damping concepts are applied in many areas of mechanical engineering, e.g. damping of turbine blades, leaf springs for trucks, car wheels, brake disks, damping of aerodynamic flutter, earthquake protection, see e. g. [1-8] as well as recent patents [9-14]. Here, undesired mechanical vibrations, which cause dynamic distortion, are suppressed by dry coulomb friction. This well known effect is based on energy dissipation and is achieved by the application of friction elements with adjustable normal forces. For more details see $[15,16]$. The lightweight damping elements are often made of composites or even of temperature resistant materials, e.g. metal, if required. Thus, these passive

*Address correspondence to this author at the DLR German Space Centre, Institute of Space Systems, Robert-Hooke-Str. 7, D-28203 Bremen, Germany; Tel.: ++49 42124420 105; Fax:++49 42124420 150;

E-mail: oliver.romberg@dlr.de elements are also applicable for temperatures where viscous damping devices fail. Depending on their application, these elements are capable of increasing the damping ratio in case of forced vibrations. The mass increase due to the additional components is almost negligible.

The mechanical principle described here has been applied for the aluminum structure of the German spacecraft demonstrator PHÖNIX [17]. In corresponding experiments (shaker tests) performed for a 1:1 scale tail model, the application of those passive damping devices based on friction elements results nearly in a duplication of the damping ratio. For those kinds of components, where dynamic loads are decisive for the design, a reduction of mechanical loading can be directly transposed to mass reduction and life span extension. Structural analyses for the PHÖNIX tail model result in a theoretical mass saving potential of $\sim 25 \%$.

Regarding the present patent DE10138250 analogue passive damping elements are placed between the face sheets of composite sandwich panels. Shahram [18] shows a patent on composite vibration damping for acoustic frequencies. Here, within a composite panel vibrations are suppressed by friction between the deforming inner structure.

\section{THEORETICAL BACKGROUND}

The functioning of friction elements is based on relative displacements of components which cause friction forces and result finally in a vibration suppressing energy dissipation. The general principle of friction elements is depicted in Fig. (1a), which shows a sketch of a vibrating component modeled as a cantilever beam. On the surface of this beam there is deposited a solid friction element (here: a friction strip). Even small vibrations of the beam lead to relative displacements between the vibrating component (I) and the friction 
element (II). The displacements cause friction forces which result finally in a vibration suppressing energy dissipation.

A simple theoretical model describing this effect is the friction oscillator which is depicted in Fig. (1b). The corresponding equation of motion is as follows:

$\mathrm{m} \ddot{\mathrm{y}}(\mathrm{t})+\mathrm{b} \dot{\mathrm{y}}(\mathrm{t})+\mathrm{c} \mathrm{y}(\mathrm{t})=\mathrm{F}_{\text {ex. }}(\mathrm{t})-\mathrm{F}_{\text {Friction }}(\mathrm{t}, \mathrm{N}, \mu)$,

where $\mathrm{y}$ is the deflection of the vibrating component, $\mathrm{m}$ is the mass of component, $b$ is the natural damping coefficient, $c$ is the stiffness of the structure, $F_{e x}$. is the excitation force (e.g. random spectrum or cyclic excitation) and $\mathrm{F}_{\text {Friction }}=$ $\mu \mathrm{N}(\mathrm{t})$ is the friction force in the contact, with $\mathrm{N}$ as normal force, $\mu$ as friction coefficient, which can be different for sliding and sticking conditions, and $\mathrm{t}$ as time.

a)

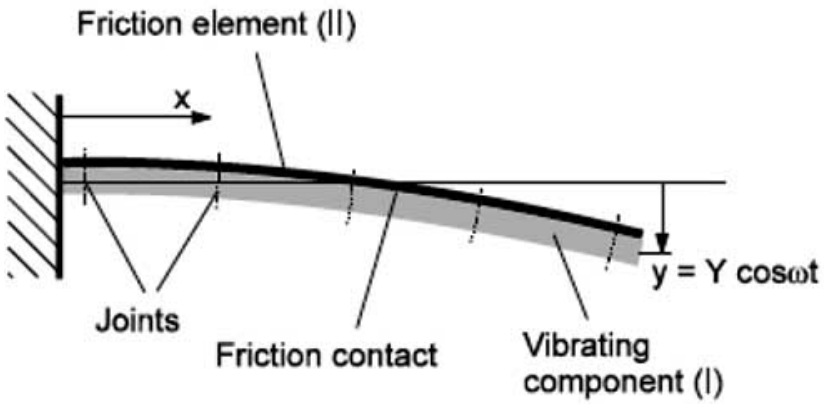

b)

\section{Simple model: \\ Friction oscillator}

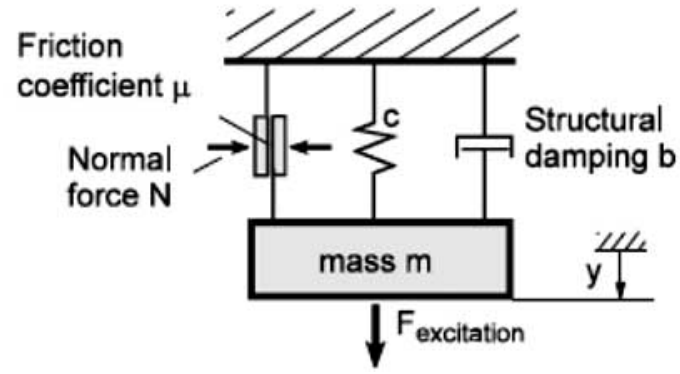

Fig. (1). Vibrating cantilever beam with friction strip (a); simple theoretical model (b).

In general, the principle of friction damping described herein can be applied on longitudinal vibrations, e.g. as piston-cylinder-system, respectively rotational vibrations. Joining elements enable an adjustment of the damping properties by variation of the normal force $\mathrm{N}$. Thus, an optimization of the friction force $F_{\text {Friction }}$ is possible.

In order to determine the optimal friction forces $\mathrm{F}_{\text {Friction, }}$ i.e. the essential optimal surface pressure $\mathrm{p}(\mathrm{x})$ between the two paired friction components, an energy balance can be drawn. Accordingly Fig. (2) shows the hysteresis of the reduced friction force $\overline{\mathrm{r}}([\overline{\mathrm{r}}]=\mathrm{N} / \mathrm{m})$ for a vibration cycle of the system according to Fig. (1). During a deformation the relative maximum displacement $\mathrm{u}(\mathrm{x})$ is split into a kinematic part $\mathrm{u}_{\mathrm{k}}(\mathrm{x})$ and an elastic part $\mathrm{u}_{\mathrm{e}}(\mathrm{x})$.

The energy $\mathrm{W}_{\text {diss }}$ dissipated per vibration cycle can be written as:

$$
W_{\text {diss }}=4 \int_{0}^{l} \bar{r}(x)\left[u_{k}(x)-u_{e}(x)\right] d x,
$$

where 1 is the length of the beam element.

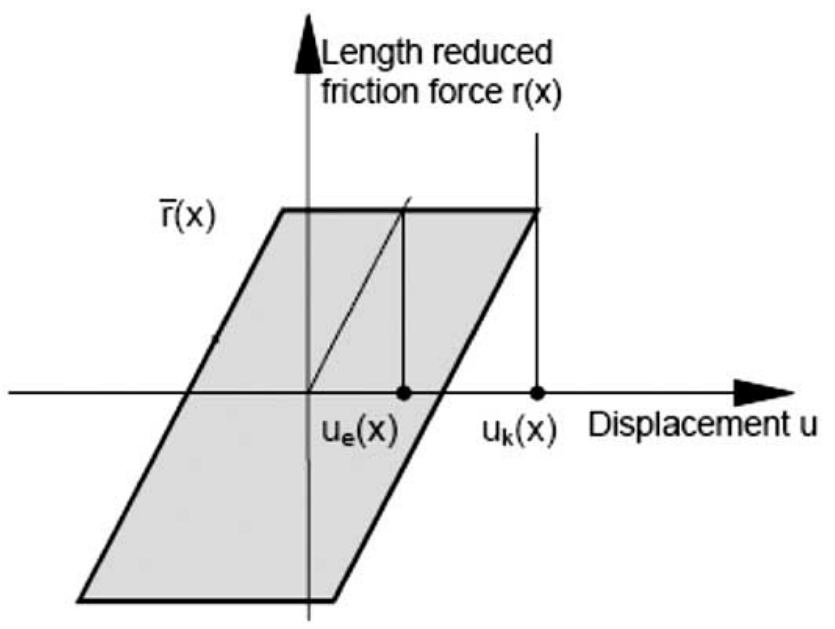

Fig. (2). Hysteresis of friction force.

The assumption of an optimized dissipation $\mathrm{W}_{\mathrm{diss}}=\max$ results in a function for the optimal contact pressure $\mathrm{p}_{\mathrm{opt}}(\mathrm{x})$, which depends beside the location $\mathrm{x}$ upon the

- Geometry of structure,

- Displacement y(x),

- Elasticity (Young's Module) and

- Friction coefficient $\mu$.

The contact pressure $\mathrm{p}(\mathrm{x})$ can be optimised by a simple mechanism or by manufacturing measures. The function $\mathrm{p}(\mathrm{x})$ is most important for the functioning of a friction element and, thus, for suppressing of dynamic loading.

In a recent patent, Browne et al. [19] study the subject of active controlled friction forces by changing the surface texture. The difficulties with respect to the design of friction elements lie in the description of the non-smooth friction processes with non-linear equations of motions. An analytical solution is possible on the basis of simple assumptions. Corresponding numerical solutions require a high calculation effort in order to optimize a friction element. With Finite Element Methods (FEM) the calculation of non smooth dynamics is connected to high computational effort. However, the mathematical treatment of non-linear dynamics linked with friction, see e.g. [20-26], is subject of intensive research world wide and is not further considered here. 


\section{CURRENT \& FUTURE DEVELOPMENT}

\subsection{Development \& Application of Principle on Light- weight Structure}

PHÖNIX, which had its maiden flight at Kiruna (Sweden) in 2004, is a sub-scaled demonstrator of the (still in development) possible future space vehicle HOPPER [27]. This large vehicle, which is foreseen as a frequently reusable space transportation system analogous to the US-ShuttleOrbiter, would have to withstand very high dynamical loads during a horizontal sled supported launch and during the reentry after sub-orbital payload deployment. Figure $\mathbf{3}$ shows results from a FEM-Analysis for the vertical tail of the vehicle performed by ASTRIUM. Furthermore, the fin, the wings as well as the airframe shell of the vehicle are vibrating structures. Due to the expected high launch and re-entry loads, here, a reduction of dynamic stress is essential for reliable operation.

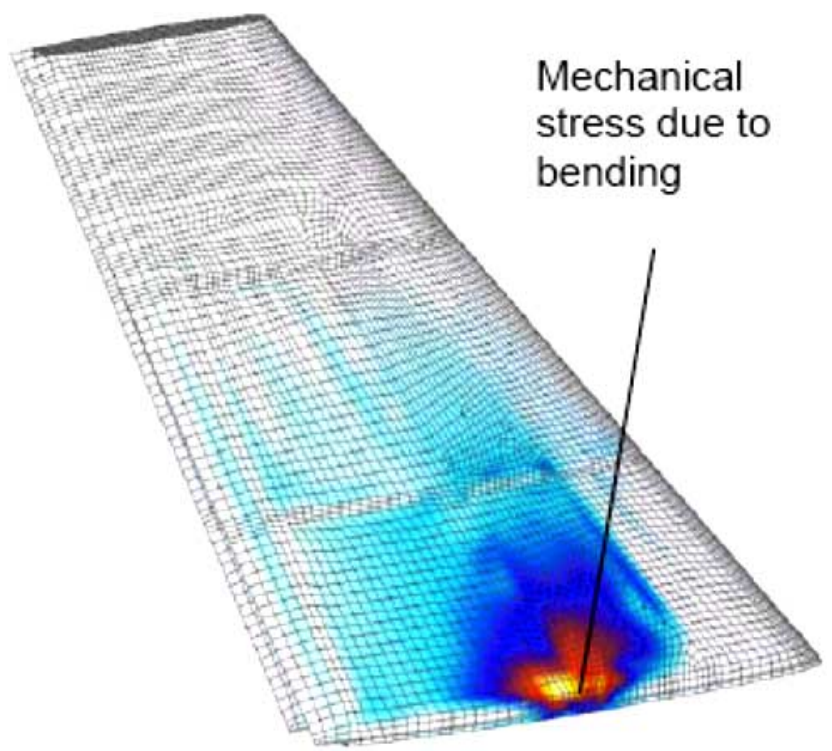

Fig. (3). Results from a structural analysis of the PHÖNIX-fin [picture: ASTRIUM, Bremen].

In the frame of experimental investigation performed by OHB-System and funded by DLR a friction damping concept for the PHÖNIX-tail was designed and tested. In the area of the main spar, see also Figs. $(\mathbf{3}, \mathbf{4})$, the highest mechanical stress is expected. For the experimental investigation and demonstration (ground vibration tests) a 1:1 model of the PHÖNIX tail was built. The structure consists mainly of three spars, four ribs and a skin, see Fig. (4a). The main spar is designed as a double T-beam. The friction elements, which were designed by the Institute of Mechanics at the University of Hannover are placed at the inner side of the main spar, as shown in Fig. (4b). Note, that the elements, as additional components, have negligible influence on the static properties of the fin. The additional mass of the friction elements amounts to $3.5 \%$ of the entire tail structure. This is considered to be negligible compared to the mass that can be saved due to the reduced dynamical loading.

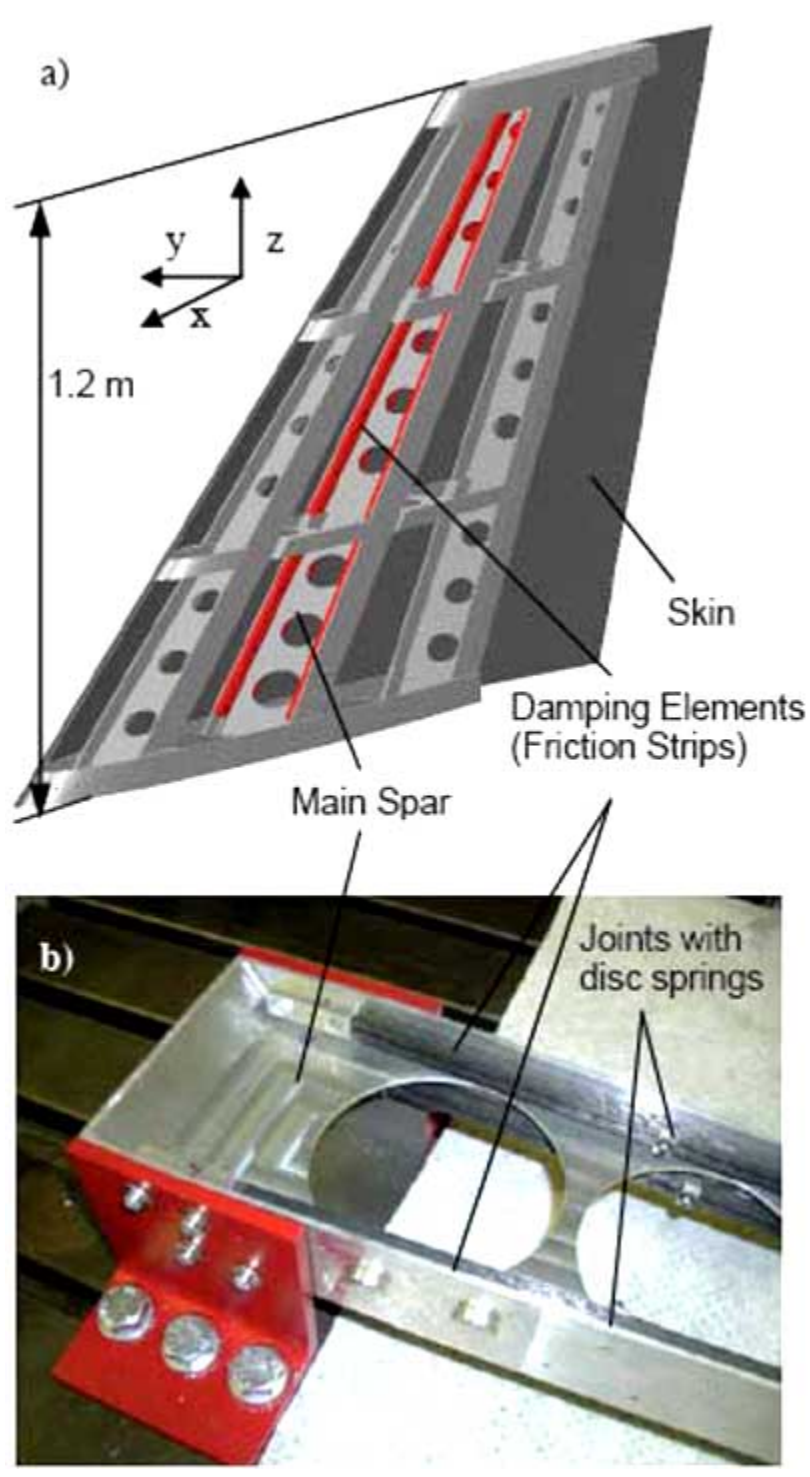

Fig. (4). Application of damping elements for the PHÖNIX-fin: entire fin schematically (a) [picture: OHB-System], photo of main spar root with damping elements (b) [photo: Institute of Mechanics, University of Hanover].

The location of the damping elements at the main spar is most important for their optimal function. The contact location requires a large distance to the neutral axis of integrated structure to get high relative displacements and damping. The damping ratio of the system depends on geometry and modulus of elasticity of the damping element. The amplitude of the bending vibration is important. too. Making use of some basic approximation, it is possible to build a model which can be described analytically. The optimal pressure in the contact, the dissipated energy and an equivalent damping ratio are calculated based on a model described in [28] and [29]. In case the material being degraded or subjected to wear and abrasion, the normal force between friction element and lightweight structure is kept constant by using disc springs, see Fig. (4b). However, any kind of property changes could not be observed for this kind of application. 
Parameter studies have been carried out to find the optimal geometry and material of the damping element for the present application. A comparison of different materials shows an advantage of Carbon Fibre Re-enforced Plastic (CFRP). Lightweight damping elements made of CFRP have the highest ratio of system damping to element mass. The analytical calculations were verified by a number of experimental tests. The damping of the $1^{\text {st }}$ bending mode of the isolated single main spar has been tested with and without damping elements. Without elements the damping ratio is $0.1 \%$. With optimized damping elements the mean value of the damping ratio is $9 \%$ and the maximum value is $16 \%$, because the damping increases with increasing amplitude of vibration. The large difference with and without damping elements can be seen in Fig. (5). Here, free vibration tests are compared.

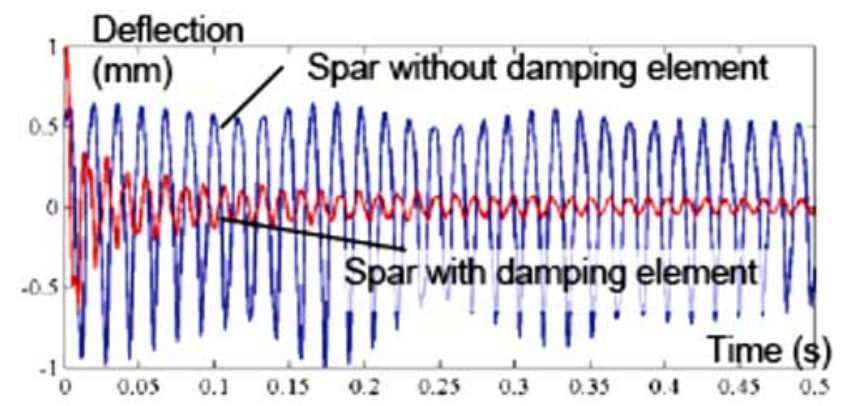

Fig. (5). Free vibration tests of the main spar with and without damping elements.

The experimental investigation for the integral fin applying spacecraft-relevant load spectra had been performed at STN-Atlas in Bremen, Germany. For the vibration tests, the damped fin was compared with the non-damped identical structure, where the fins were mounted successively onto a shaker, see Fig. (6). The tests were focused on the first bending mode in lateral direction, i.e. the "soft" tail-axis. The structural response according to free vibration tests, sinus- as well as random and shock excitation has been investigated.

In the following a brief extract of the results is shown. A more detailed description can be found in [17]. A simple free vibration test shows an increase of the damping ratio $\mathrm{D}$ from $\mathrm{D}=3,3 \%$ (reference) to $\mathrm{D}=6,2 \%$ (damped tail). The structural response of a sinus-sweep can be seen in the Figs. (7 and 8). The frequencies had been considered within a spectrum between $20 \mathrm{~Hz}$ and $2 \mathrm{kHz}$. The different curves represent the sensor locations along the tail. In the first eigenmode the highest values appear naturally at the fin peak. A comparison of Figs. (7 and 8). shows also the damping effect, i.e. a doubling in ratio. Note, that here logarithmic axes are applied, which suppress the first impression.

The simulation of relevant loads ("launch" \& "re-entry") had been realised by application of random spectra, which are defined for the US-Shuttle payload bay, for details see [30]. For comparison between the damped and non-damped configuration Figs. (9 and 10) zoom the results to a small spectrum around the $1^{\text {st }}$ eigenfrequency of ca. $42 \mathrm{~Hz}$. Further,

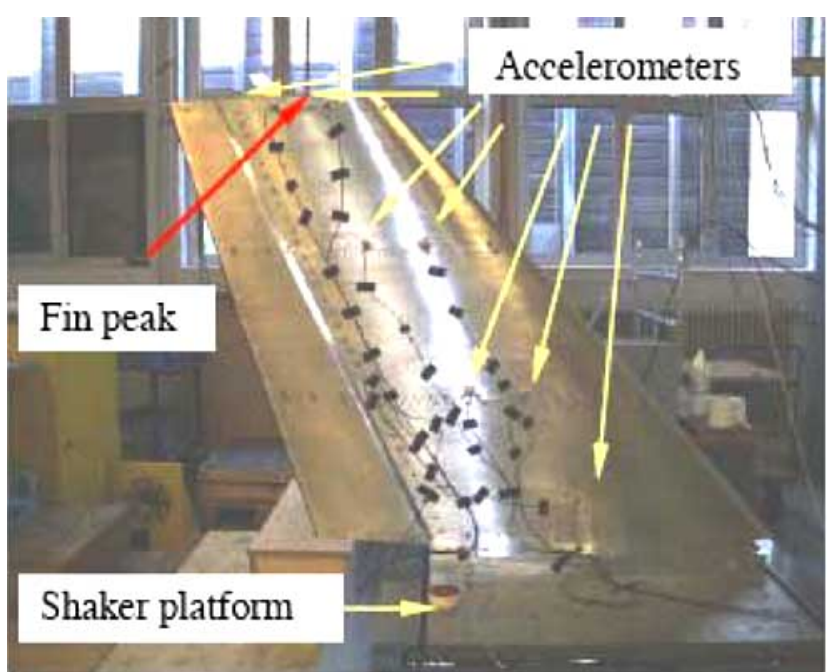

Fig. (6). PHÖNIX-tail model mounted on shaker, [photo: OHBSystem].

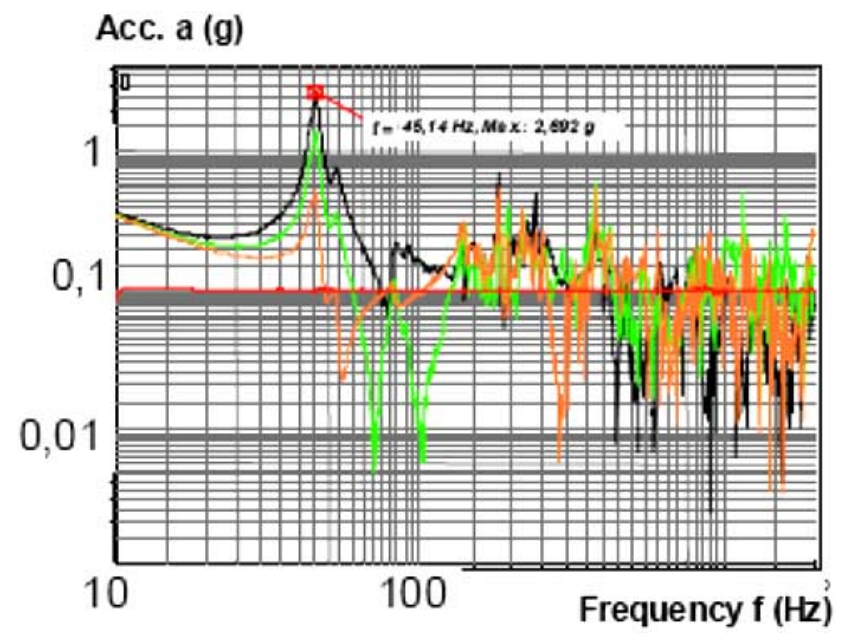

Fig. (7). Sinus response spectrum (acceleration) for the nondamped reference tail [17].

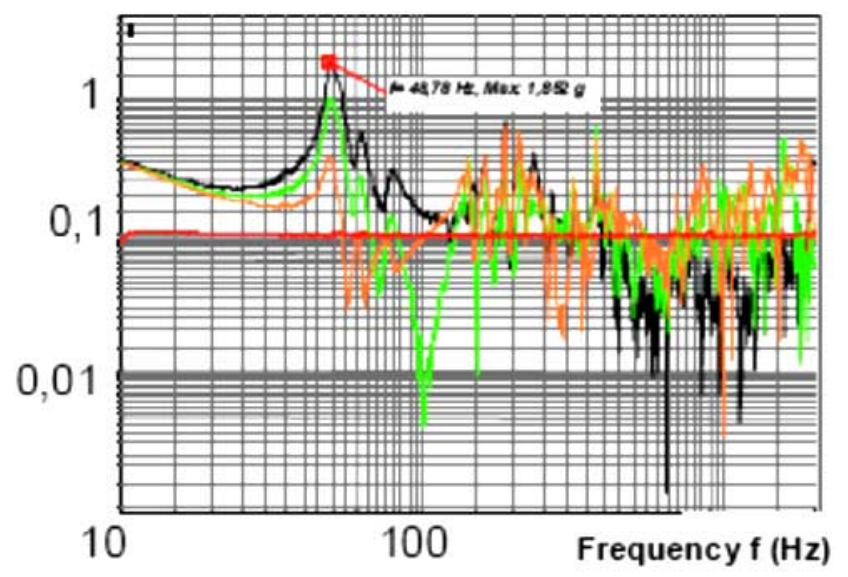

Fig. (8). Sinus response spectrum (acceleration) for the tail with damping elements [17]. 


\section{$\operatorname{PSD}\left(g^{2} / \mathrm{Hz}\right)$}

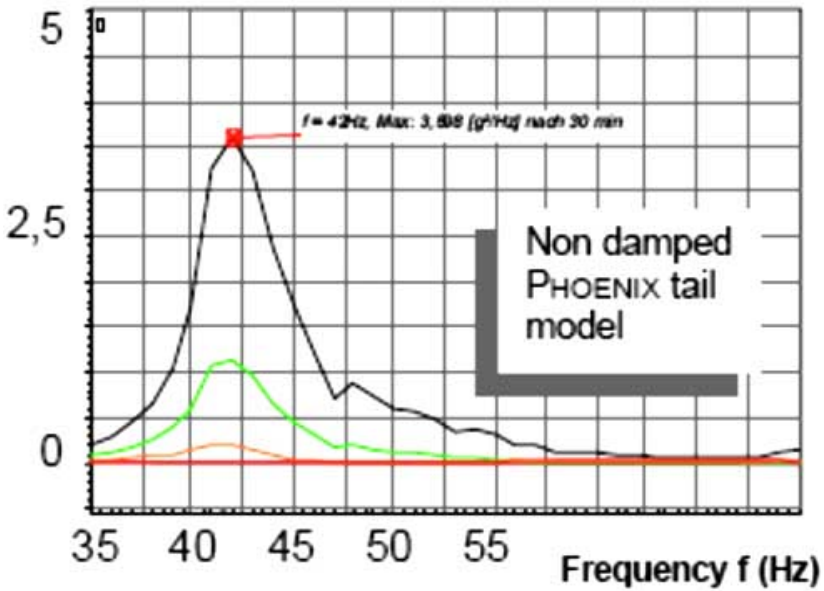

Fig. (9). Random response spectrum for the non-damped reference tail for "30 minutes launch / re-entry" (zoomed around eigenfrequency, linear plot) [17].

\section{$\operatorname{PSD}\left(\mathrm{g}^{\mathrm{g}} / \mathrm{Hz}\right)$}

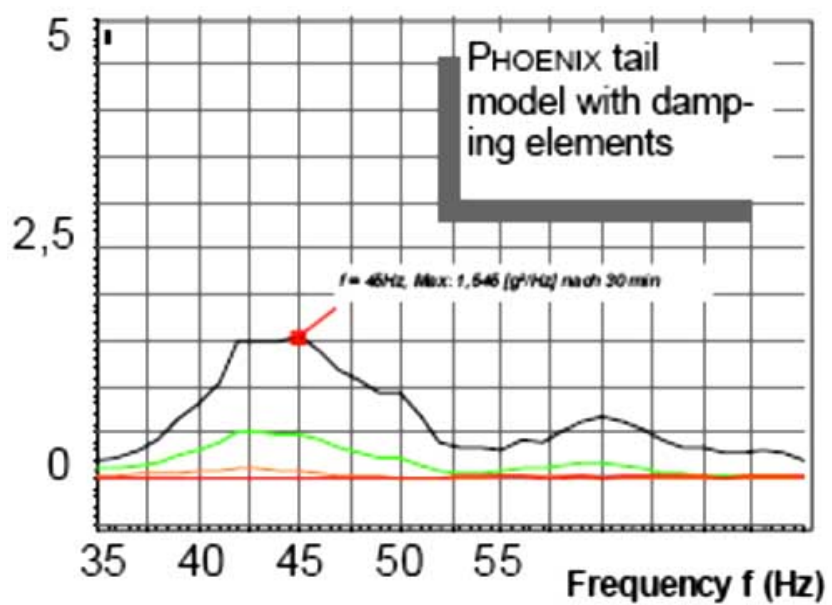

Fig. (10). Random response spectrum for the tail with damping elements for "30 minutes launch / re-entry" (zoomed around $1^{\text {st }}$ eigenfrequency, linear plot) [17].

the axes are plotted linearly. Here, the vibration suppression after long term loading ("30 minutes re-entry") is also demonstrated.

In summary, it can be stated that the passive damping elements, as investigated in the frame of described activities, increase the damping ratio by a factor of 2 .

\subsection{Experimental Test on Sandwich Panel}

In the following, the above explained concept is applied for composite sandwich panels, which is the direct subject of the here addressed relevant patent DE10138250 from November 2008. In order to fulfill lightweight requirements it is applied for aluminum as well as Glass- and Carbon Fibre Reinforced Plastics (GFRP \& CFRP). According to the rele- vant applied patent, the damping is increased by using friction elements within, i.e. between the layers of the panels, because an outside application often is disabled or impossible due to geometrical or design constraints. Further, a major requirement claims that the static behavior, i.e. the static strength, is not effected by the damping measure.

Figure 11 shows a sketch of a simple demonstration setup. It consists of a cantilever beam with $1 \mathrm{~m}$ length and $10 \mathrm{~cm}$ width equipped with inner friction elements, whereas its vibration is compared to an identical non damped reference beam. The sandwich structure is built of two CFRP layers with an intermediate aluminum honeycomb of $10 \mathrm{~mm}$ height, see also Fig. (12). The damping element, which consists of a stack of two friction strips made of thin GFRP plates (Fig. (13)), is fixed between the facesheets of the sandwich panel. This friction element is placed where the smallest curvature radii appear in case of structural deformation $\left(1^{\text {st }}\right.$ eigenmode vibration, see Fig. (11)). Small curvature radii (high curvature) mean large relative displacements and, thus, high energy dissipation between the strips.

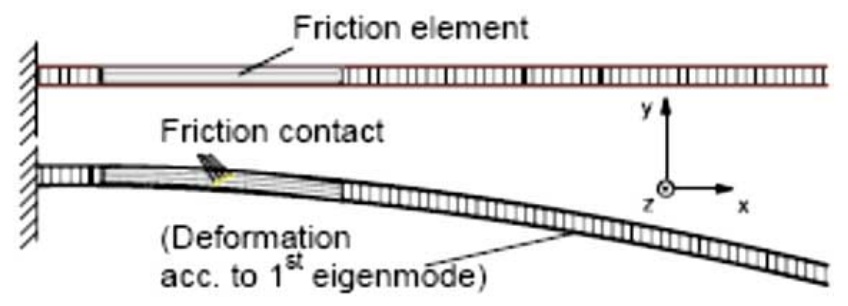

Fig. (11). Test set-up for friction elements integrated in a sandwich panel.

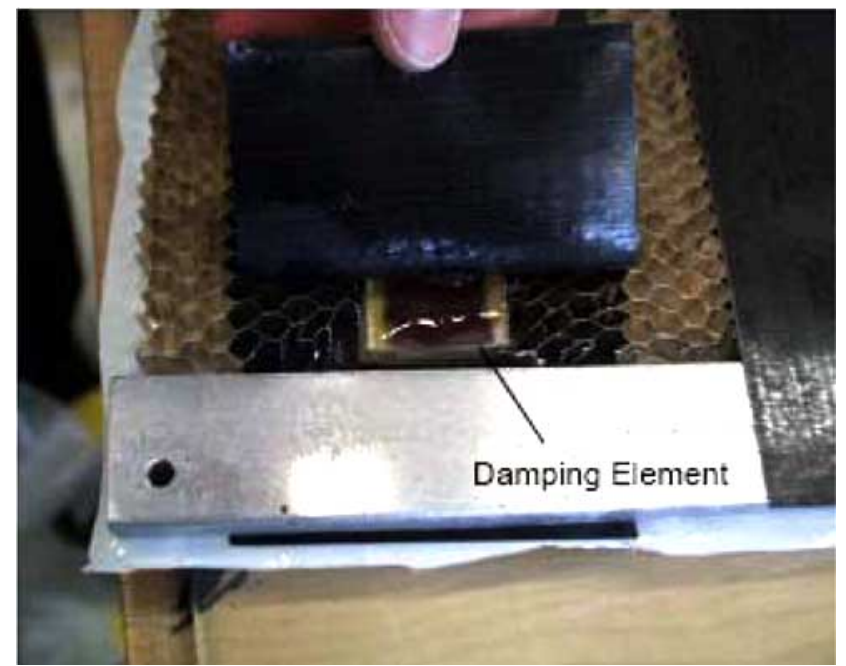

Fig. (12). Stacked friction element within honeycomb between facesheets of sandwich structure.

Both the cantilever beams, including the one with the friction element and the reference beam, had been rigidly clamped at their roots between two steel blocks to create a low damped support (nearly ideal rigid restraint), where the 

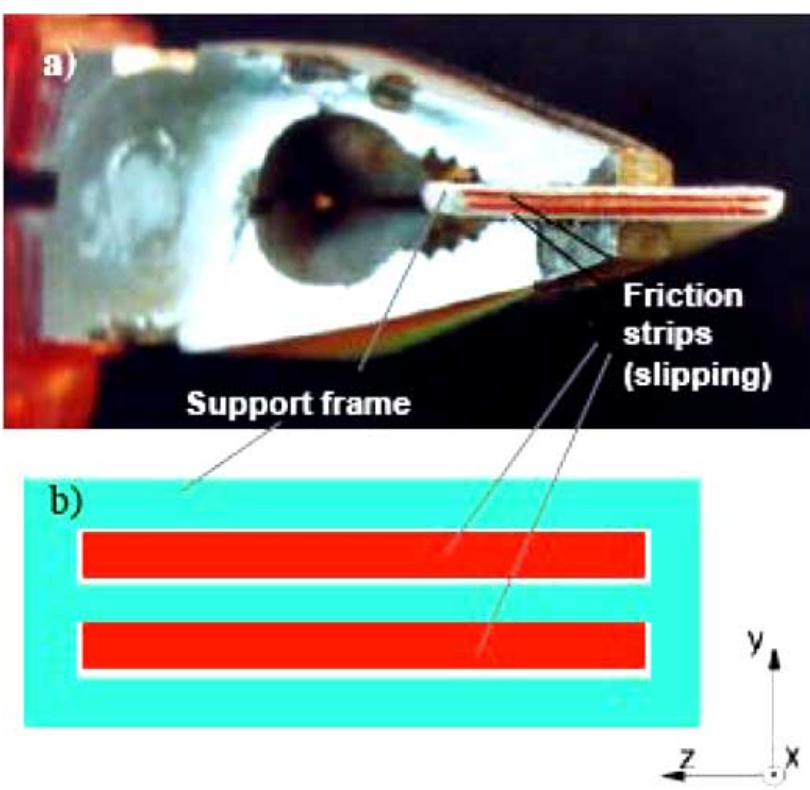

Fig. (13). a) Cross section of friction element with two slipping friction strips (red) integrated into a frame (green); for showing scale and for clarification purpose, here held by a pliers, b) Sketch of friction element: Support frame (green) and slipping friction strips (red).

principle is shown in Fig. (11). left hand. At the start of the test, the free tops of the beams had been statically deflected using thin wires. After cutting the wires the beams start free vibrating mainly in the $1^{\text {st }}$ eigenmode (classical free oscillation test).

Results from that free vibration test are shown in Fig. (14). for the damped Beam II compared to Beam I (reference, no artificial damping). For the test the free end of the beams were equipped with accelerometers. In the diagrams the free vibration curve is plotted vs time. The diagrams show the dynamic behavior after initial displacement of the cantilever beams. The eigenfrequency of both beams is $f_{o}=$ $23 \mathrm{~Hz}$. The damping ratio for the specimen with damping element is almost doubled. The ratio $\mathrm{D}_{0}=1,7 \%$ (no friction elements) is increased to $\mathrm{D}_{\mathrm{FE}}=3,3 \%$ (with friction element).

In the following the resulting potential regarding mass saving and life-span extension for corresponding damped lightweight structures is briefly discussed.

\section{MASS SAVING POTENTIAL}

The damping ratio $\mathrm{D}$ has a large influence on the structural response and, thus, on the stress. If the damping factor $\mathrm{D}$ increases the amplitudes and, thus, the stress $\sigma$ decreases. Depending on the geometry and the materials using a friction element the damping coefficient $\mathrm{D}$ can be increased drastically depending upon geometry and application. e.g., concerning the previously described PHÖNIX-demonstrator, for further increase of the damping ratio, it is plausible to equip all three spares with elements instead of only the main spar, see Fig. (4). For rough calculation regarding the mass saving
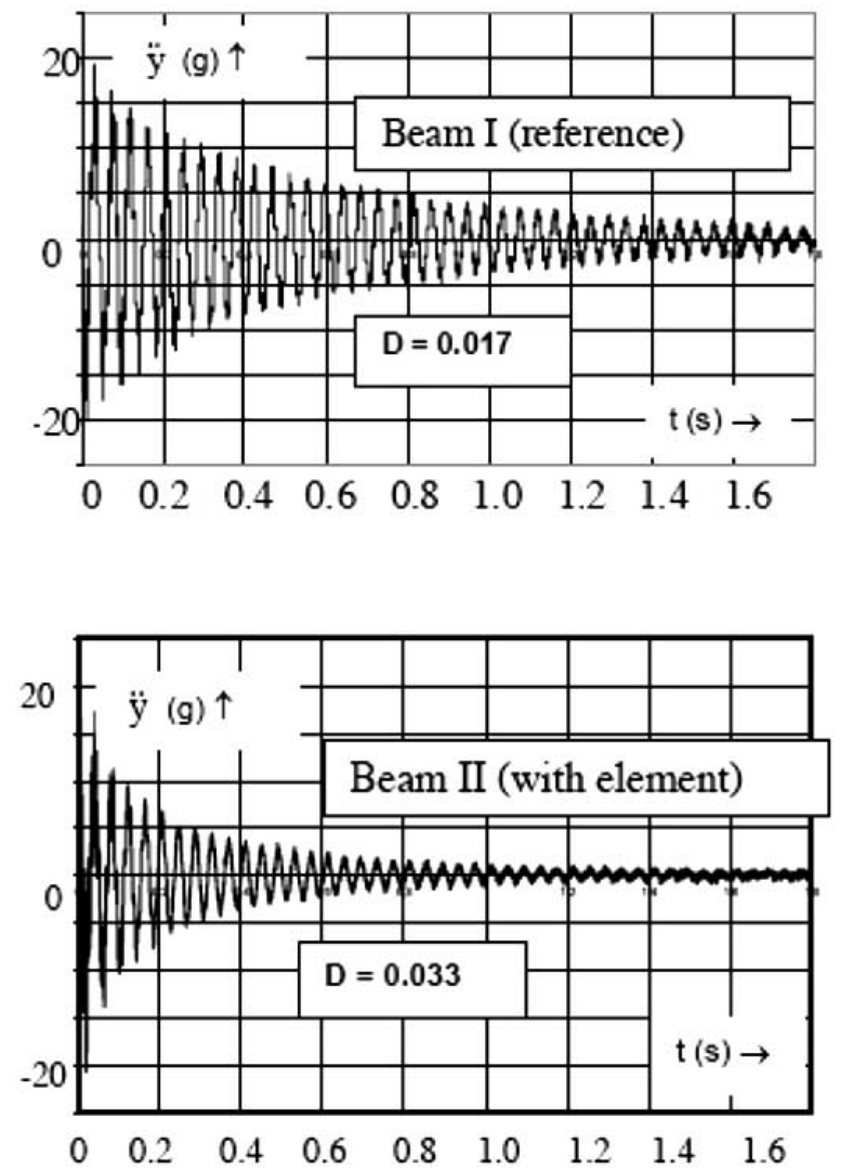

Fig. (14). Results from vibration test (free vibration after initial displacement; damped and non-damped beam).

potential, some material thicknesses of the model with increased damping can be reduced. Corresponding structural analyses, i.e. random response analyses under the assumption that here the dynamical loads are design drivers, for both the damped and a non-damped model had been carried out (for details, see [31]). Within an iterative process, for the additional damped model the lightweight design was further optimized until the stress $\sigma_{\mathrm{m}}$ of the natural-damped model is achieved. Here, for some components the material thickness could be reduced to $70 \%$ of the original. Regarding the skin, the buckling behavior only leads to a mass reduction of $20 \%$ since for the buckling safety $\mathrm{S}_{\mathrm{B}}>2$ is required. Finally, the performed theoretical investigation results in a mass saving of ca. $25 \%$ assuming a doubling of the damping factor. Note, that the additional mass of the damping device has to be subtracted from the saved mass. In the present case the elements share $3,5 \%$ of the structure.

\section{LIFE SPAN EXTENSION}

The influence on the life span can be clarified by means of $\mathrm{S}-\mathrm{N}$-curves [32], where the critical stress (crack) is depicted versus the load cycles (= life span in case of continuous vibrating structures). Depending upon the material as well as upon the structure, there are empirical results showing a 
decreasing boundary stress with an increasing number of load cycles. Instead of steel, which has a horizontal tangent of the critical stress for high number of load cycles, aluminum alloys as well as composite materials have a steady decreasing S-N-curve. Thus, the life spans of lightweight materials relevant here are directly effected by the number of load cycles in combination with the vibration amplitude. Assuming millions of load cycles of a vibrating lightweight structure, the stress would be reduced due to the damping increase. Thus, also the life span of integral structure increases. The degree of life span extension depends strongly upon the material, the structure and the load cases and can be quantified for individual cases only. In any case the impact of long term application, wear and temperature impact must also be considered.

\section{CONCLUSIONS}

The recent patent DE10138250 (November 2008) described in the present paper points out a relatively simple and low cost possibility for load reduction with respect to dynamically loaded lightweight structures. The damping ratio of a structural system has a large influence on the structural response and, thus, on the stress. If the damping factor increases, the stress decreases drastically, which benefits the application of lightweight structures subjected to dynamical loads.

In the frame of the activities described in this paper, a system of passive friction damping elements has been designed which is amongst others placed between the face sheets of composite sandwich panels. Corresponding experiments with passive damping devices based on friction elements result in a duplication of the damping ratio for sandwich panels. In parallel a similar method has been applied for a demonstration model of the PHÖNIX flight vehicle fin which resulted in a significant damping increase on subsystem level and a duplication of the damping ratio for the integral system.

For all kinds of components, where dynamic loads are decisive for the design a reduction of mechanical loading can be directly transposed to mass reduction and life span extension. Structural analyses for the fin model with increased damping results in a mass saving potential of about $20 \%$. Investigations regarding this mass saving potential as well as concerning the life span extension due to increased damping has been performed. Depending on the material as well as upon the structure, empirical results show a decreasing boundary stress with an increasing number of load cycles. Thus, life span is directly affected by the number of load cycles in combination with the vibration amplitude. The degree of life span extension depends strongly upon the material, the structure and the load cases and can be quantified for individual cases only. In any case the impact of long term application, wear and temperature impact must also be considered.

The advantages of the applied damping elements result directly in cost reduction since on the one hand the lightweight design can be further optimized and on the other hand the maintenance and exchange effort can be reduced. Moreover, safety and reliability can be increased.
However, further investigations of the methods described in this paper on a technology level are necessary. Note, that only the physical principle is demonstrated in this paper. For instance, the tests were performed with room temperature, only. Note, that in practice higher temperatures might appear caused by the outside environment or even due to friction effects. Increased temperatures as well as very low temperatures might change the coefficient of friction and, thus, the damping factor. Therefore, further investigations have to be performed concerning this issue. Another critical issue is the possible abrasion effect on the friction elements after long time operation. Moreover, the results of the tests with the single main spar confirm a strong dependency of the damping factor upon the amplitudes. Here, also further theoretical as well as experimental investigations are necessary. Moreover, it is reasonable to extend these kinds of investigations to other dynamically loaded lightweight (sandwich) structures, i. e. shells, plates, grids or rods used in many areas of mechanical or civil engineering, e.g. also for earthquake protection and others. For these kinds of extended application, for more complex and may be non beam-like structures, the optimum location and geometry of corresponding damping elements have to be determined carefully. Moreover, the friction pairing i.e. the materials of the elements have to be chosen considering the structure material as well as the case of application, since there is no optimum pairing. For each use case, the application potential has to be evaluated individually based on geometry-, material-, load- as well as modal analyses.

\section{ACKNOWLEDGEMENTS}

The work was partly funded by the DLR (Deutsches Zentrum für Luft- und Raumfahrt) in the frame of the German research programme ASTRA (Ausgesuchte Systeme und Technologien für zukünftige RaumtransportsystemAnwendungen). Parts of the work have been performed in frame of a DLR-contract with OHB-System supported by the Institute of Mechanics of the University of Hannover.

\section{CONFLICT OF INTEREST}

There is no conflict of interests to declare.

\section{REFERENCES}

[1] Sextro W, Popp K. Dynamical behaviour of a bladed disk with friction dampers. Proc of EUROMECH-2 $2^{\text {nd }}$ European Nonlinear Oscillation Conf, Prague, September 1996; 1: 391-4.

[2] Allen JM. Friction damping in compressor blade dovetail attachements. ASME 1986; 86-GT-137.

[3] Chen S, Sinha A. Probabilistic method to compute the optimal slip load for a mistuned bladed disk assemply with friction dampers. ASME Bound Volume DE-18.3, 1989.

[4] Sextro W, Popp K, Wolter I. Three-dimensional vibration of bladed disk assemblies with fric-tion dampers. Proc ISROMAC-7, Honolulu, Hawai 1998; Vol. B.

[5] Sinha A, Griffin JH. Friction damping of flutter in gas turbine engine airfoils. J Aircraft 1983; 20(4): 372-6.

[6] Sinha A, Griffin JH. Stability of limit cycles in frictionally damped and aerodynamically un-stable rotor stages. J Sound Vib 1985; 103(3): 341-56.

[7] Sinha A, Griffin JH. Influence on friction dampers on torsional flutter. ASME Paper 85-GT-170, 1985. 
[8] Panning L. Design of friction elements for vibration damping of turbine blades, VDI-fortschrittsberichte, 11 ed. No. 328, VDIVerlag Duesseldorf 2005.

[9] Dessouki, O. S., Lowe, B. D., Riefe, M. T., Monsere, P. J., Sandar, M. Friction damped brake drum. US20100018819 (2010).

[10] Drachmann, M. Damping of wind turbine blade vibration. WO2010025732 (2010).

[11] Smith, B. J. Friction damping system for a railway truck. US20100186621 (2010).

[12] Dessouki, O.S., Lowe, B.D., Riefe, M.T., Doescher, M.T., Yuhas, J.J. Coulomb friction damped disc brake caliper bracket. US7604098 (2009).

[13] Nishimura, T. Friction damper. JP2009041585 (2009).

[14] Kaname, O. Friction damper device. JP2009014193 (2009).

[15] Gaul L, Becker J. Damping prediction of structures with bolted joints. J Shock Vib 2001; 17: 359-71.

[16] Gaul, L. Active element for vibration reduction of components. DE19702518 (2000).

[17] Romberg O, Tausche M, Kröger M. Passive Damping of a Vertical Tail. 54 Int Astronautical Congress IAC 2003, Bremen, 29 Sept03 Oct 2003.

[18] Shahram, Z. Composites for sound control application. US20090189111 (2009).

[19] Browne, A.L., Johnson, N.L., Mankame, N.D., Bucknor, N.K., Mc Knight, G.P., Barvosa-carter, W., Keefe, A.C., Henry, C.P., Herrera, G.A. Active material based bodies for varying surface texture and frictional force levels. US20090047197 (2009).

[20] Hinrichs N, Oestreich M, Popp K. On the modelling of friction oscillators. J Sound Vib 1998; 216(3): 435-59.
[21] Oestreich M, Hinrichs N, Popp K. Bifurcation and stability analysis for a non-smooth friction oscillator. Appl Mech 1996; 66(5): 30114.

[22] Popp K, Stelter P. Stick-slip vibrations and chaos. Philos Trans R Soc Lond A 1990; 332(1624): 89-105.

[23] Earles SWE, Williams EJ. A linearized analysis for frictionally damped systems. J Sound Vib 1972; 24(4): 445-58

[24] Goodman L, Brown G. Energy dissipation in contact friction: Constant normal and cyclic tangential loading. Trans ASME J Appl Mech 1962; 29: 17-22.

[25] Guran A, Pfeiffer F, Popp K. Dynamics with friction-modelling, analysis and experiment. World Scientific Publishing: Singapore Part I, 1996; Part II, 2000

[26] Stelter P. Non-linear vibrations of friction excited structures. Prog Rep VDI Edition 11(137): Duesseldorf 1990.

[27] ASTRA System Concepts Studies: Concept 1 - Sub-orbital Hopper Summary Description, Draft, June 2001.

[28] Klamt K. Optimization of vibration damping due to joint patch friction in structures. Prog Rep VDI $11^{\text {th }}$ ed. No. 134, Duesseldorf 1990 (in German).

[29] Kroeger M, Reckmann H, Popp K, Romberg O. Friction strip damping in lightweight structures. Soc Appl Math Mech Padua 2003.

[30] Romberg O, Janovsky R, Wienss W. Mechanical damping for future RLV-structures. $3^{\text {rd }}$ European Conf on Launcher Technology, Strasbourg, France, 11-14 December, 2001.

[31] Romberg O. Passive friction damping, ASTRA WP 4000: Structures, Design \& Materials, Final Report ASTRA-OHB-4220-SB, October 2003 (in German)

[32] Military Handbook (5H). Metallic Materials \& Elements for Aerospace Vehicle Structures 1998. 